\title{
Kwetsbaarheid in tijden van pandemie
}

André Weel, Ruud Meij, Kevin De Decker en Peter van Wenum

Aangeboden ter publicatie op 1 juni 2020

Aangeboden in definitieve vorm op 8 juni 2020

Geaccepteerd voor publicatie op 23 juni 2020

\section{Inleiding}

Op 15 maart 2020 kondigde de Nederlandse overheid verregaande maatregelen af in verband met de COVID -19-pandemie. Centraal daarin stond de drastische beperking van sociale en fysieke contacten met andere mensen. Scholen en bedrijven werden gesloten; wie dat kon moest thuiswerken. Daarmee begon een lockdownperiode van 11 weken. Voor veel mensen, vooral voor mensen met een chronische aandoening, was dat een spannende en onzekere episode. Al snel werd duidelijk dat deze laatste groep een verhoogde kans had op een ernstig ziektebeloop en op overlijden. Sterven aan COVID-19 is een dramatische dood gebleken omdat dat zeer vaak gebeurt op een intensivecareafdeling onder omstandigheden die een normaal menselijk contact met verzorgenden en een afscheid van dierbaren onmogelijk maken.

Op 11 mei en 1 juni 2020 zijn stapsgewijze versoepelingen van maatregelen van kracht geworden. Zo zijn op 1 juni restaurants en musea weer opengegaan, weliswaar onder voorwaarden van een maximum van 30 bezoekers en het bewaren van anderhalve meter afstand. Voor veel mensen met een chronische aandoening geeft dat nieuwe onzekerheid omtrent het al dan niet deelnemen aan het maatschappelijk verkeer, waaronder ook het hervatten van het werk.

In dit artikel bespreken we de casus van een medewerkster van een museum die extra kwetsbaar is als het om COVID-19 gaat. Bij zijn advisering van werkgever en

Dr. André N.H. Weel is bedrijfsarts en epidemioloog, werkzaam voor IKA Ned BV te Amsterdam.

Drs. Ruud Meij is filosoof, werkzaam bij Governance \& Integrity BV te Amsterdam, en bij de Universiteit voor Humanistiek te Utrecht.

Kevin De Decker is verzekeringsarts, werkzaam bij UWV te Amsterdam.

Peter van Wenum is bedrijfsarts, werkzaam bij Van Altena \& De Jongh Bedrijfsartsen BV te Alkmaar, en voorzitter van de Commissie Beroepsuitoefening en Ethiek van de NVAB. Correspondentieadres: andre.weel@ika-ned.nl werknemer komt de bedrijfsarts voor een lastig dilemma te staan. Om de voorliggende morele vraag te beantwoorden past de bedrijfsarts de methode van morele oordeelsvorming toe. ${ }^{1}$ De essentie van deze methode bestaat hierin dat recht wordt gedaan aan alle bij de betreffende advisering betrokken personen. Morele oordeelsvorming is een methodisch onderzoek dat uit zeven stappen bestaat, waarbij de argumenten voor de verschillende handelingsopties, voor zover dat mogelijk is, worden benoemd als beginsel- of gevolgargumenten. Beginselargumenten verwijzen naar rechten van betrokken personen en wegen daarom zwaarder dan gevolgargumenten. Een aantal louter op feiten berustende argumenten kan niet nader worden geclassificeerd.

Allereerst presenteren de auteurs een geanonimiseerde casus uit de praktijk van één van hen. Aansluitend worden de zeven stappen van de methode morele oordeelsvorming doorlopen. Daarbij fungeert de inbrengende bedrijfsarts als subject. Hij of zij moet immers de uiteindelijke beslissing nemen. De visie van deze bedrijfsarts is niet automatisch identiek aan die van ieder van de auteurs.

\section{De casus}

Op het open spreekuur krijgt een bedrijfsarts bezoek van Renée van den Abeelen, een vrouw van 44 jaar die als operationeel leidinggevende werkt in een museum. Zij regelt de dagelijkse gang van zaken in het museum en heeft ook beheer en onderhoud in haar portefeuille. Haar functie leent zich niet of nauwelijks voor thuiswerk. Het museum zal op 1 juni 2020 weer open gaan na een lockdownperiode van 11 weken wegens de COVID-19-pandemie. Van den Abeelen behoort tot de door het RIVM gedefinieerde kwetsbare groepen als het om COVID-19 gaat. ${ }^{2}$ Zij lijdt aan astma en heeft daarvan enkele malen per jaar een exacerbatie. De klachten kunnen dan maandenlang aanhouden. Vooral virale infecten kunnen astmaklachten bij haar uitlokken. $Z e$ is onder behandeling van een longarts. Ook mist ze een nier. Op dit moment is ze klachtenvrij, maar ze heeft haar werkgever laten weten dat ze het 
niet verantwoord vindt om op 1 juni haar werk in het museum weer op te pakken, omdat zij tot een risicogroep behoort met een verhoogde kans op een ernstig beloop na besmetting met het coronavirus. Daarom wil zij elk contact met collega's en museumbezoekers vermijden. Misschien dat ze het over een paar maanden wel aandurft als er minder besmettingen zijn, maar nu nog niet. Al met al is Van den Abeelen behoorlijk angstig en gespannen door de hele situatie.

De bedrijfsarts zegt toe met de werkgever te zullen overleggen over een oplossing, maar een uur later belt de museumdirecteur hem al op. Voor de heropening van het museum is een uitgebreid veiligheidsplan gemaakt waarbij rekening is gehouden met alle maatregelen van de museumbranche. Zo geldt er een maximum van 30 bezoekers en moeten medewerkers en bezoekers anderhalve meter afstand tot andere personen bewaren. Alle personeelsleden zijn gekend in de maatregelen rond de heropening. Allen, behalve Van den Abeelen, hebben ermee ingestemd. Het museum kampt met ernstige financiële problemen vanwege de lockdown. Het is nu alle hens aan dek. Ook Van den Abeelen kan niet worden gemist.

De directeur vindt Van den Abeelen niet loyaal. Hij neemt het haar kwalijk dat zij niet wil komen. Dat heeft een ongunstige uitstraling naar andere medewerkers. Bovendien maakt Van den Abeelen er zelf geen geheim van dat zij gewoon boodschappen doet, tennist en af en toe thuis bezoek ontvangt. Dan kan zij toch ook naar het museum komen!

Stap 1: Voor welke keuze sta ik? Wat is mijn voorlopig oordeel? En wat is mijn voornaamste bezwaar? Als bedrijfsarts sta ik voor een lastige keuze. Wat moet ik werkgever en werknemer adviseren? Is het verantwoord dat Van den Abeelen weer aan het werk gaat in het museum? Zij behoort met haar chronische longaandoening duidelijk tot de mensen met verhoogde kans op een ernstig beloop van een COVID-19-infectie. Aan de andere kant lijkt het erop dat het museum adequate maatregelen heeft getroffen om de besmettingskans voor bezoekers en personeelsleden te minimaliseren. De keuze is daarom lastig omdat hier sprake lijkt van tegengestelde belangen. Het museum heeft belang bij een maximale personeelsinzet. Van den Abeelen heeft belang bij het minimaliseren van de voor haar geldende gezondheidsrisico's. De beslissing die ik als bedrijfsarts hier moet nemen vraagt dat ik recht doe aan de ander. Dat wil zeggen dat mijn beslissing voldoende rekening moet houden met de rechten, belangen en wensen van allen die bij mijn beslissing zijn betrokken. Ik formuleer twee alternatieven voor mijn advies.
Alternatief A: Het is verantwoord dat mevrouw Van den Abeelen per 1 juni weer aan de slag gaat in het museum, omdat het museum alle vereiste maatregelen heeft genomen om de besmettingskans voor de medewerkers te verlagen.

Alternatief B: Mevrouw Van den Abeelen moet voorlopig niet in het museum aan de slag gaan. Voor haar is het risico van COVID-19-besmetting te groot.

Mijn voorlopige keuze is alternatief A. Iedereen, ook mevrouw Van den Abeelen, moet zijn of haar steentje bijdragen bij het versoepelen van de lockdown, in dit geval om het museum op te starten. Het bezwaar van deze keuze is dat ik niet tegemoetkom aan de angst van de werknemer voor besmetting.

\section{Stap 2: Welke betrokkenen hebben rechten, belangen of wensen die geraakt worden door de te nemen beslissing?}

Van den Abeelen als werknemer, de museumdirecteur als werkgever, andere personeelsleden, de museumbezoekers, de bedrijfsarts.

\section{Stap 3: Wie neemt de uiteindelijke beslissing?} De beslissing omtrent het advies dat werkgever en werknemer van mij vragen, ligt bij mij.

\section{Stap 4: Heb ik nadere informatie nodig om mijn beslissing op verantwoorde wijze te nemen?}

Heb ik aanvullende medische, juridische of situationele informatie nodig? Als bedrijfsarts ken ik Van den Abeelen al langere tijd vanwege eerdere perioden van langdurig verzuim: enkele malen wegens een exacerbatie van haar astma, en eenmaal vanwege een nieroperatie. Op grond van de eerste publicaties over risicogroepen en mortaliteit bij COVID-19 is bij haar de kans op longcomplicaties significant verhoogd.

Juridisch lijkt de zaak duidelijk. Mevrouw van den Abeelen heeft momenteel geen gezondheidsklachten die haar arbeidsongeschikt maken voor haar werk in het museum. Zij is niet ongeschikt voor haar werk. Dat sluit overigens niet uit dat haar werk momenteel wel ongeschikt is voor haar. De werksituatie verdient mijn aandacht.

Wat dat laatste betreft liggen de kaarten duidelijk. Van den Abeelen is als operationeel manager de spin in het web in het museum. Daarnaast is zij bij technische problemen, bijvoorbeeld van de klimaatregelingsinstallatie, de expert bij uitstek. Haar werk leent zich er niet voor om dat van huis uit te doen. Op internet zoek ik de COVID-19-maatregelen voor de museumbranche op. Die zijn door het museum nauwgezet toegepast.

Ten aanzien van haar privéactiviteiten (tennissen, boodschappen doen) heeft Van den Abeelen desgevraagd verklaard dat zij daarbij de situatie wat betreft afstand houden tot anderen veel beter in de hand heeft dan 
het geval is binnen de museummuren. Zij tennist in enkelspel, alleen met haar eigen partner, en gaat thuis douchen. Boodschappen doet zij 's morgens vroeg en ook daarbij bewaart ze ruimschoots de anderhalve meter afstand tot anderen. In het museum wordt ze voortdurend benaderd en aangesproken door medewerkers en bezoekers.

\section{Stap 5: Wat zijn de argumenten voor elk van beide beslissingsopties?}

In deze stap worden alle argumenten verzameld die een rol kunnen spelen in de morele afweging. De argumenten voor elk van beide alternatieven van de handeling verdienen even veel aandacht. Alle argumenten moeten worden toegelaten. Die aanpak voorkomt dat belangrijke of onwelgevallige argumenten al in een vroegtijdig stadium uit beeld verdwijnen. Er is dus een morele reden voor deze aanpak, namelijk dat zo de rechten, belangen en wensen van alle betrokkenen het beste kunnen worden meegewogen.

Deze stap maakt het mogelijk om op een open manier over het morele onderzoek van gedachten te wisse- len. De clou zit hier in het - al dan niet gezamenlijk - zoeken naar een zo volledig mogelijk beeld van alle argumenten.

\section{Stap 6: Benoem de argumenten als beginsel- of gevolgenargument. Weeg de argumenten. Benoem de belangrijkste argumenten voor en tegen. Neem de definitieve beslissing.}

In deze stap worden de argumenten gewogen en wordt een uiteindelijk oordeel gevormd. Het is daarbij behulpzaam om een onderscheid te maken tussen verschillende typen morele argumenten.

Er zijn argumenten die te maken hebben met de rechten van betrokken personen en instellingen. Bij deze argumenten drukt een beginsel de verplichting uit waarmee aan het recht van de betrokkene tegemoet wordt gekomen. We spreken dan ook van beginselargumenten.

Er zijn daarnaast ook argumenten die betrekking hebben op belangen en wensen van betrokkenen. Belangen en wensen worden meestal verwoord als gevolgen die de beslissing voor de betrokkenen met zich meebrengt. Een

\begin{tabular}{|c|c|}
\hline $\begin{array}{l}\text { Argumenten voor werkhervatting in het museum } \\
\text { (alternatief } A \text { ) }\end{array}$ & $\begin{array}{l}\text { Argumenten om voorlopig 'in lockdown' (dus thuis) te } \\
\text { blijven (alternatief B) }\end{array}$ \\
\hline $\begin{array}{l}\text { Doordat het museum afdoende beschermingsmaatrege- } \\
\text { len heeft getroffen, in overeenstemming met het proto- } \\
\text { col van de museumbranche, is de besmettingskans in } \\
\text { het museum aanzienlijk verminderd. }\end{array}$ & $\begin{array}{l}\text { Werknemer behoort duidelijk tot een kwetsbare groep. } \\
\text { Het risico op ernstige gezondheidsschade en overlijden } \\
\text { na besmetting is voor haar verhoogd. Het is mijn plicht } \\
\text { als bedrijfsarts om mensen tegen het risico van gezond- } \\
\text { heidsschade door het werk te beschermen. }\end{array}$ \\
\hline $\begin{array}{l}\text { De bijdrage van alle personeelsleden is nodig om het } \\
\text { museum financieel te laten overleven. }\end{array}$ & $\begin{array}{l}\text { Werknemer kiest er zelf voor om niet nu aan het } \\
\text { werk te gaan. Bij werkhervatting in het museum kan } \\
\text { de kans op besmetting niet worden uitgesloten. Voor } \\
\text { deze werknemer zijn de gevolgen daarvan onevenredig } \\
\text { groot: veel groter dan voor medewerkers zonder een } \\
\text { longaandoening. In dat geval wordt van haar een offer } \\
\text { gevraagd. Dat betekent dat zij het recht heeft om zelf } \\
\text { te beslissen of zij dit offer wil brengen. }\end{array}$ \\
\hline $\begin{array}{l}\text { Werknemer was tijdens de lockdownperiode ook bui- } \\
\text { tenshuis actief met tennissen, boodschappen etc. Haar } \\
\text { angst voor besmetting valt kennelijk wel mee. }\end{array}$ & $\begin{array}{l}\text { Werknemer wil geen enkel risico op besmetting lopen. } \\
\text { Zij vindt voor zichzelf de besmettingskans in het muse- } \\
\text { um nog te hoog, ondanks de getroffen maatregelen. }\end{array}$ \\
\hline $\begin{array}{l}\text { Zij heeft momenteel geen gezondheidsklachten. De } \\
\text { werkgever mag verwachten dat zij haar werk in het } \\
\text { museum oppakt. }\end{array}$ & $\begin{array}{l}\text { Werknemer heeft het wettelijk recht om zich ziek te } \\
\text { melden bij dreigend gevaar voor de gezondheid op het } \\
\text { werk. }\end{array}$ \\
\hline $\begin{array}{l}\text { De besmettingsindicatoren (ziekenhuisopnamen, } \\
\text { IC-bedbezetting, sterfte) zijn al weken aan het dalen. } \\
\text { Werknemer hoeft dus niet bang te zijn om aan het } \\
\text { werk te gaan. }\end{array}$ & $\begin{array}{l}\text { Werknemers angst voor besmetting is reëel: het } \\
\text { coronavirus veroorzaakt nog dagelijks tientallen } \\
\text { nieuwe besmettingen, ziekenhuisopnames en sterfe- } \\
\text { vallen. Als bedrijfsarts moet ik met die angst rekening } \\
\text { houden. Het moet nog blijken of de daling van het } \\
\text { aantal besmettingen etc. aanhoudt na verlichting van } \\
\text { de lockdown. }\end{array}$ \\
\hline $\begin{array}{l}\text { Als werknemer hervat } \\
\text { werkdruk ervaren. }\end{array}$ & \\
\hline
\end{tabular}


argument dat let op de gevolgen van beslissingen heet een gevolgenethisch argument of gevolgenargument. Een gevolgenethische redenering rekent met de gevolgen van een beslissing en zegt dat díe beslissing uit moreel oogpunt de beste is, die het grootste welzijn oplevert voor het grootste aantal mensen.

Omdat rechten een ondergrens bepalen, kunnen die wel geschonden worden doordat er andere rechten tegenoverstaan die meer gewicht hebben, maar niet door gevolgenargumenten. In de uiteindelijke afweging zijn de rechten van betrokkenen meer bepalend dan de belangen en wensen. Beginselargumenten perken de werking in van gevolgenargumenten.

We zien aan de linkerkant één beginselargument, tevens het belangrijkste argument voor werkhervatting van Van den Abeelen. Daarom is het rood gemarkeerd. Hier speelt het beginsel van geen schade toebrengen, in dit geval het voorkómen van onnodig lijden door een ernstige besmetting. Het museum neemt passende maatregelen. Daardoor wordt de besmettingskans voor alle werknemers en voor de bezoekers van het museum verminderd, maar niet weggenomen.

Aan de andere kant zien we drie beginselargumenten. Het rekening houden met de verhoogde kwetsbaarheid van een werknemer weerspiegelt het beginsel van geen schade toebrengen. Dat is aan de rechterkant het belangrijkste argument. Een tweede beginselargument ligt in het recht van elke werknemer om zich bij gezondheidsgevaar tot de bedrijfsarts te wenden en zich eventueel ziek te melden. Dat recht is ook in de wet vastgelegd. Tenslotte heeft de werknemer het recht op zelfbeschikking als zij besluit niet in het museum te gaan werken.

Bij de afweging gaat het er niet om aan welke kant de meeste beginselargumenten staan. Wat het zwaarst is, moet het zwaarst wegen. In dit geval is dat lastig, omdat beide rood gemarkeerde argumenten teruggaan op het biomedische beginsel van 'geen schade toebrengen'. Het beginselargument aan de rechterkant (alternatief B) heeft specifiek betrekking op mevrouw Van den Abeelen, terwijl het aan de linkerkant (alternatief A) gaat om het verminderen van de besmettingskans voor alle medewerkers. Daarom moet eerstgenoemd beginselargument zwaarder

\begin{tabular}{|c|c|}
\hline $\begin{array}{l}\text { Argumenten voor werkhervatting in het museum } \\
\text { (alternatief } A \text { ) }\end{array}$ & $\begin{array}{l}\text { Argumenten om voorlopig 'in lockdown' (dus thuis) te } \\
\text { blijven (alternatief B) }\end{array}$ \\
\hline $\begin{array}{l}\text { Doordat het museum afdoende beschermingsmaatrege- } \\
\text { len heeft getroffen, in overeenstemming met het proto- } \\
\text { col van de museumbranche, is de besmettingskans in } \\
\text { het museum aanzienlijk verminderd. BEGINSEL }\end{array}$ & $\begin{array}{l}\text { Werknemer behoort duidelijk tot een kwetsbare groep. } \\
\text { Het risico op ernstige gezondheidsschade en overlijden } \\
\text { na besmetting is voor haar verhoogd. Het is mijn plicht } \\
\text { als bedrijfsarts om mensen tegen het risico van gezond- } \\
\text { heidsschade door het werk te beschermen. BEGINSEL }\end{array}$ \\
\hline $\begin{array}{l}\text { De bijdrage van alle personeelsleden is nodig om het } \\
\text { museum financieel te laten overleven. GEVOLG }\end{array}$ & $\begin{array}{l}\text { Werknemer kiest er zelf voor om niet nu aan het } \\
\text { werk te gaan. Bij werkhervatting in het museum kan } \\
\text { de kans op besmetting niet worden uitgesloten. Voor } \\
\text { deze werknemer zijn de gevolgen daarvan onevenredig } \\
\text { groot: veel groter dat voor medewerkers zonder een } \\
\text { longaandoening. In dat geval wordt van haar een offer } \\
\text { gevraagd. Dat betekent dat zij het recht heeft om zelf } \\
\text { te beslissen of zij dit offer wil brengen. BEGINSEL }\end{array}$ \\
\hline $\begin{array}{l}\text { Werknemer was tijdens de lockdownperiode ook bui- } \\
\text { tenshuis actief met tennissen, boodschappen etc. Haar } \\
\text { angst voor besmetting valt kennelijk wel mee. }\end{array}$ & $\begin{array}{l}\text { Werknemer wil geen enkel risico op besmetting lopen. } \\
\text { Zij vindt voor zichzelf de besmettingskans in het muse- } \\
\text { um nog te hoog, ondanks de getroffen maatregelen. }\end{array}$ \\
\hline $\begin{array}{l}\text { Zij heeft momenteel geen gezondheidsklachten. De } \\
\text { werkgever mag verwachten dat zij haar werk in het } \\
\text { museum oppakt. }\end{array}$ & $\begin{array}{l}\text { Werknemer heeft het wettelijk recht om zich ziek te } \\
\text { melden bij dreigend gevaar voor de gezondheid op het } \\
\text { werk. BEGINSEL }\end{array}$ \\
\hline $\begin{array}{l}\text { De besmettingsindicatoren (ziekenhuisopnamen, } \\
\text { IC-bedbezetting, sterfte) zijn al weken aan het dalen. } \\
\text { Werknemer hoeft dus niet bang te zijn om aan het } \\
\text { werk te gaan. }\end{array}$ & $\begin{array}{l}\text { Werknemers angst voor besmetting is reëel: het } \\
\text { coronavirus veroorzaakt nog dagelijks tientallen } \\
\text { nieuwe besmettingen, ziekenhuisopnames en sterfe- } \\
\text { vallen. Als bedrijfsarts moet ik met die angst rekening } \\
\text { houden. Het moet nog blijken of de daling van het } \\
\text { aantal besmettingen etc. aanhoudt na verlichting van } \\
\text { de lockdown. }\end{array}$ \\
\hline $\begin{array}{l}\text { Als werknemer hervat zullen haar collega's een } \\
\text { werkdruk ervaren. GEVOLG }\end{array}$ & \\
\hline
\end{tabular}


worden gewogen. De andere twee beginselargumenten aan de rechterkant, waarin de autonomie van mevrouw aan de orde komt, bevestigen deze keuze.

Alles afwegende, kies ik voor alternatief B met het kleinst mogelijke gezondheidsrisico voor mijn cliënt en adviseer ik mevrouw Van den Abeelen om op 1 juni niet aan het werk te gaan in het museum, maar zich thuis beschikbaar te houden. Datzelfde meld ik ook aan haar werkgever. Ik geef dit advies in weerwil van het feit dat het museum er alles aan heeft gedaan om de werksituatie optimaal in te richten en er een kans bestaat op een faillissement.

\section{Tussenstap: schadebeperking. Welke acties zijn mogelijk om de schade en de nadelen van de genomen beslissing te beperken of te compenseren?}

Mijn advies is een maand geldig; daarna wil ik een nieuwe afweging maken, waarbij ik de landelijke COVID-19-incidentie over de maand juni, alsmede de ervaringen in het museum met de gereguleerde openstelling in mijn afwegingen zal betrekken. Ik overleg met de werkgever of het mogelijk is dat de werknemer intussen een vorm van thuiswerk gaat doen, zonder fysieke contacten met bekende of onbekende personen, en telefonisch bereikbaar blijft voor operationele vragen.

\section{Stap 7: Peil wat de inbrenger en de meedenkers voelen bij de genomen beslissing.}

Alle argumenten zijn meegewogen bij mijn beslissing. Werknemer is het ermee eens. De werkgever is verbaasd. "Wij proberen met man en macht het museum weer open te krijgen en nu dit! Het hele personeel staat achter de maatregelen en werkt mee behalve Renée!” De bedrijfsarts legt uit dat de maatregelen voor iedereen hetzelfde zijn, maar dat de consequenties wat werken betreft per persoon kunnen verschillen. Voor de meeste mensen is werkhervatting verantwoord, maar voor Van den Abeelen lijkt dat op dit moment (nog) niet het geval.

\section{Conclusie}

Het morele oordeel van de bedrijfsarts is wel voorlopig, maar het is niet relatief of subjectief. Het is de uitkomst van een zorgvuldige weging van alle rechten en belangen van iedere mens of instantie die door een bepaalde handeling wordt geraakt. Volgens die weging is de keuze op alternatief B gevallen.

\section{De 'moraal' van deze casus}

Het is belangrijk om onderscheid te maken tussen de begrippen 'kans' en 'risico'. Een kans is een statistische grootheid die de waarschijnlijkheid van een gebeurtenis uitdrukt. Een risico houdt ook rekening met de grootte van het effect. Risico is, in een formule uitgedrukt, het product van kans en effect.

Zo is voor het museum, na tenuitvoerlegging van de beschermende maatregelen, de besmettingskans voor allen die er gaan werken in principe gelijk. Het risico is evenwel groter voor werkenden met een verhoogde kwetsbaarheid, doordat voor hen de gevolgen van een besmetting veel ernstiger kunnen zijn. Dat speelt mee bij de afweging die hier gemaakt is. Zie het eerste argument van alternatief $B$.

Deze casus kan bijdragen aan goede bedrijfsgezondheidszorg bij het verlichten van de lockdown. De coronapandemie en de lockdown is voor chronisch zieke en kwetsbare patiënten een bijzonder ingrijpende ervaring geweest en is dat nog steeds. Het zijn de patiënten met een onderliggend lijden, zoals mevrouw Van den Abeelen, die het hardst worden geraakt door COVID-19. Het zijn ook deze patiënten, zoals in de verpleeghuizen, die tijdens de crisis onvoldoende zijn beschermd. Bij de verlichting van de lockdown verdienen deze patiënten extra zorg en aandacht van de bedrijfsarts. Op de eerste plaats vanwege het nog steeds aanwezige risico dat zij alsnog door het coronavirus kunnen worden besmet, met mogelijk ernstige tot zelfs fatale gevolgen. Ten tweede vanwege de angst, de onzekerheid en de druk waarmee werknemers als mevrouw Van den Abeelen mogelijk te kampen hebben. De bedrijfsarts is dan het baken dat kwetsbare werknemers tegen de ziekte, de druk en de valse schaamte ('ik ben een lafaard') en schuldgevoelens ('ik laat mijn collega's zitten') beschermt. Werknemers als Van den Abeelen zouden het recht moeten hebben om in vergelijkbare situaties zelf te beslissen of ze aan het werk willen. Maar misschien moet de bedrijfsarts ze daar wel eerder voor behoeden. 'Wacht maar even hoe de verlichting van de lockdown uitpakt'. Ondertussen kan de bedrijfsarts adviseren over preventieve maatregelen tegen COVID-19-besmetting.

De moraal: bij een pandemie gaat de bescherming van de gezondheid - in brede zin - vóór arbeidsre-integratie en participatie. De bedrijfsarts is weer even alleen maar heelmeester.

\section{Literatuur}

1. Governance \& Integrity. Werkboek Begeleiden van een Moreel Beraad. Amsterdam: Governance \& Integrity BV, 2008.

2. Risicogroepen COVID-19 volgens RIVM, te raadplegen op https://www.rivm.nl/coronavirus-covid-19/risicogroepen

3. Museumprotocol, te raadplegen op https://museumcontact. $\mathrm{nl} /$ bestanden/200520mvprotocolvoorveiligeenverantwoordeheropeningvanmuseapdf 